COMMENT. Rasmussen's syndrome of focal seizures and progressive hemiparesis begins in early childhood, is often preceded by a minor febrile and probable viral illness, and is manifested by epilepsia partialis continua and intellectual deterioration. Short-term reduction in seizure frequency has been reported following IV immunoglobulin and long-term oral prednisolone treatments at the Montreal Neurological Institute. (See Progress in Pediatric Neurology III, 1997;p127).

\title{
EARLY WITHDRAWAL OF ANTIEPILEPTIC DRUGS
}

Recurrence rate, risk factors for recurrence, and outcome in 161 children after early withdrawal of antiepileptic drugs (AEDs) were studied at Leiden University and other centers in The Netherlands. The probability of remaining seizure free at 24 months was $51 \%$ for 78 patients whose AEDs were discontinued after a 6 month seizure-free period, and $52 \%$ for 83 patients with a 12 month period of seizure control. Risk factors for relapse were partial epilepsy, onset of seizures at 12 years or older, known seizure etiology, and epileptiform EEG. After a mean 42 month follow-up, 129 (80\%) were seizure free for at least 1 year, two thirds without AEDs. (Peters ACB, Brouwer OF, Geerts AT et al. Randomized prospective study of early discontinuation of antiepileptic drugs in children with epilepsy. Neurology March 1998;50:724-730). (Reprints: Dr ACB Peters, Department of Child Neurology, University Hospital Utrecht and Wilhelmina Children's Hospital, PO Box 85500, 3508 GA Utrecht, The Netherlands).

COMMENT. Early withdrawal of antiepileptic therapy after 6 or 12 months seizure control is followed by seizure recurrence in $50 \%$ of patients, regardless of the treatment duration. A comparison of these results of early drug withdrawal with previous reports of later withdrawal $(2,3$, or 4 years) suggests an optimal seizure-free treatment period of 2 years. The shorter duration of seizure-free therapy results in a higher relapse rate. (See Progress in Pediatric Neurology III, 1997;pp115-122).

\section{GENETIC TWIN STUDIES OF EPILEPSY SYNDROMES}

The genetics of epilepsy syndromes was studied by an evaluation of 253 twin pairs at the University of Melbourne, Australia. One or both twins had seizures, Among monozygous (MZ) and dizygous (DZ) twin pairs, $44 \%$ and $10 \%$ were concordant for seizures, respectively. Both twins had the same major epilepsy syndromes in $94 \%$ of concordant $\mathrm{MZ}$ pairs and $71 \%$ of concordant DZ pairs. The concordance rates for generalized epilepsies, both idiopathic and symptomatic, were greater than those for partial epilepsies. Febrile seizures and unclassified epilepsies had intermediate rates. Genetic factors play a role in all epilepsy syndromes but especially in generalized epilepsies. (Berkovic SF, Howell RA, Hay DA, Hopper JL. Epilepsies in twins: Genetics of the major epilepsy syndromes. Ann Neurol April 1998;43:435-445). (Respond: Dr Samuel F Berkovic, Department of Neurology, Austin and Repatriation Medical Centre, Heidelberg (Melbourne), Victoria 3084, Australia).

COMMENT. The authors conclude that genetics of epilepsy is syndromespecific rather than a broad genetic predisposition. Their findings support those of Lennox WG who pioneered the research on genetics of epilepsy in twins in the early 1950s. I was privileged to be a Fellow in his "Seizure Clinic" at Harvard when he and a psychologist co-worker reported a series of 173 twin pairs (Lennox WG, Jolly DH. Seizures, brain waves and intelligence tests of epileptic twins. A Res 
Nerv \& Ment Dis Proc 1954;33:325-345). Lennox not only found evidence for an "inherited epileptic predisposition" but he also demonstrated a "pattern-specific" genetic tendency, stronger in twins with generalized seizures (grand mal) than with partial seizures (psychomotor). "Grand mal appeared concordantly in $82 \%$ of monozygotic and in $15 \%$ of dizygotic twins." "Concordance of psychomotor attacks was $38 \%$ in monozygotic pairs and $5 \%$ in the dizygotic." In petit mal seizures, concordance was $75 \%$ among $\mathrm{MZ}$ twins and absent in $\mathrm{DZ}$ twins. Lennox also reported the concordance of 3 per sec spike-and-wave EEG dysrythmia in 16 of 19 $\mathrm{MZ}$ twin pairs and none of $14 \mathrm{DZ}$ twin pairs.

Epilepsy phenotypes and genotypes of Angelman syndrome were compared in 20 patients at the University of California, Los Angeles, School of Medicine (Minassian BA, DeLorey TM, Olsen RW et al. Angelman syndrome: Correlations between epilepsy phenotypes and genotypes. Ann Neurol April 1998;43:485-493). Patients were selected on clinical cytogenetic and molecular diagnosis of AS and all had characteristic EEGs with bifrontal and diffuse $1-3 \mathrm{~Hz}$ slow waves or slow and sharp waves. Maternally inherited chromosome 15q11-13 deletions were associated with severe intractable epilepsy, whereas UBE3A gene mutations and uniparental disomy occurred with mild epilepsy.

\section{MIGRAINE AND RELATED DISORDERS}

\section{PRECIPITANTS OF CYCLIC VOMITING}

The precipitants and etiological factors in 32 patients aged 2 - 22 years (mean, 12 years) with cyclic vomiting syndrome (CVS) compared to 64 controls were evaluated by parental questionnaire at the Princess Margaret Hospital for Children, Perth, Australia. The most prevalent precipitants were stress (47\%), infections (44\%), and foods (28\%). Accompanying features included headache (59\%) and behavioral withdrawal (59\%), lethargy (56\%) and crying (34\%). Migraine occurred more frequently in association with CVS than in controls (38\% cf $9 \%$ ). Other medical problems found more frequently in the CVS group were forceps delivery, developmental delay, coordination difficulties, and gastroesophageal reflux. Antiemetic medications utilized in 28 were useful in only 7 (28\%). Antihistamines, antimigraine drugs and anticonvulsants had been prescribed in too few patients to permit evaluation. CVS was considered a migraine variant. (Withers GD, Silburn SR, Forbes DA. Precipitants and aetiology of cyclic vomiting syndrome. Acta Paediatr March 1998;87:272-277). (Respond: Dr D Forbes, Department of Paediatrics, University of Western Australia, Princess Margaret Hospital for Children, GPO Box D184, Perth, WA 6001, Australia).

COMMENT. Migraine is one of the many proposed theories in etiology of cyclic vomiting. In this Australian series, migraine was diagnosed using parental questionnaires in $38 \%$ compared to $9 \%$ of controls. Recurrent abdominal pain, a common presenting symptom among children with migraine occurred in only $21 \%$, a frequency not significantly different from the $16 \%$ in controls. Epilepsy was reported in only one patient, but the incidence of accompanying behavioral symptoms during attacks was remarkably high. Electroencephalograms might have uncovered cases of partial complex temporal lobe involvement and ictus emeticus.

In a report of 33 children with cyclic vomiting from the Children's Medical Center, Boston, 7 (21\%) had a history of complex partial or generalized epilepsy, and $25(76 \%)$ had epileptiform EEGs, some temporal in localization, compatible with a diagnosis of epilepsy (Millichap JG, Lombroso CT, Lennox WG. Cyclic 